Témoigner Témoigner. Entre histoire et mémoire

Getuigen Revue pluridisciplinaire de la Fondation Auschwitz

$124 \mid 2017$

La musique dans les camps

\title{
Come and see (Elem Klimov)
}

\section{Brecht Capiau}

\section{OpenEdition}

\section{Journals}

Édition électronique

URL : https://journals.openedition.org/temoigner/5698

DOI : 10.4000/temoigner.5698

ISSN : 2506-6390

\section{Éditeur :}

Éditions du Centre d'études et de documentation Mémoire d'Auschwitz, Éditions Kimé

Édition imprimée

Date de publication : 2 avril 2017

Pagination : 13-16

ISBN : 978-2-930953-00-7

ISSN : 2031-4183

Référence électronique

Brecht Capiau, «Come and see (Elem Klimov)», Témoigner. Entre histoire et mémoire [Online], 124 | 2017, Online op 30 novembre 2021, geraadpleegd op 01 décembre 2021. URL: http://

journals.openedition.org/temoigner/5698; DOl: https://doi.org/10.4000/temoigner.5698 


\section{COME AND SEE (ELEM KLIMOV)}

DVD 'Toen Hij het vierde zegel verbrak, hoorde ik de kreet van het vierde dier: "Kom en Kijk!" En daar verscheen een vaalgroen paard. En die erop zat, zijn naam was de Dood, en Hades kwam achter hem aan. En hem werd macht gegeven over het vierde deel van de aarde, om te doden met het zwaard en met hongersnood en met de pest en door de wilde dieren der aarde.' (De Apocalyps of Openbaring van Johannes)

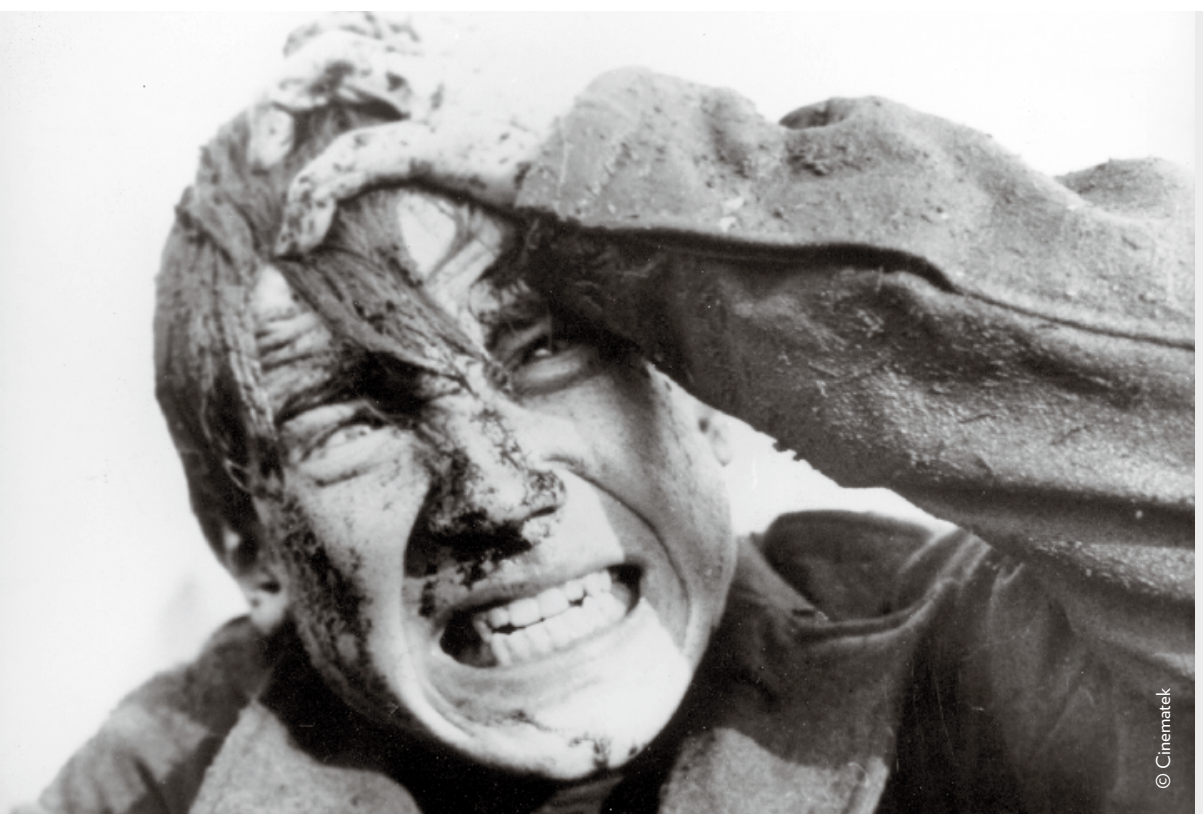

\section{Come and See} zal op dinsdag 30 mei vertoond worden tijdens de Filmclub 'Verdoken beelden' van de vzw Auschwitz in Gedachtenis. Die staat dit jaar in het teken van 'Verloren jeugd'.

Meer info: www.cineclub.brussels Cinema AVENTURE Centrumgalerij Kleerkopersstraat 15 1000 Brussel

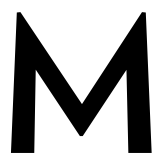
oskou, 9 mei 2015. Met een indrukwekkend militair defilé herdenkt Rusland de zeventigste verjaardag van de overwinning op nazi-Duitsland. Meer dan 16000 soldaten marcheren plechtstatig over het Rode Plein. Ondanks de aanwezigheid van een twintigtal staatsleiders en vele kijklustigen die zich verdringen bij de dranghekkens, voelt Poetin zich vrij 'eenzaam'. Veel Westerse landen hebben immers hun kat gestuurd. Deze politieke daad kan op verschillende manieren geïnterpreteerd worden. Enerzijds toont het Westen op een krachtige manier aan dat het niet akkoord gaat met de annexatie van de Krim en maant het Poetin aan om in te binden. Anderzijds kan de afwezigheid ook de indruk wekken dat de Europese leiders geen interesse hebben voor het lijden van de Sovjetbevolking tijden de Tweede Wereldoorlog. Het eerste is aan te moedigen, het tweede te betreuren.

Niemand zal ontkennen dat de Sovjet-Unie immense offers heeft gebracht tijdens de Tweede Wereldoorlog. Wel kunnen we vraagtekens plaatsen bij de manier waarop Rusland en West-Europa omgaan met dat verleden, en ons afvragen in hoeverre er sprake is van politieke recuperatie. In westerse ogen waren alle culturele producten (onder andere films en boeken) uit de USSR over deze periode een vorm van 'Sovjetpropa- •.. 
• ganda'. De USSR probeerde dan weer krampachtig de mythe van 'De Grote Patriottische Oorlog' in stand te Klimov uit 1985, is atypisch in dit opzicht om Elen 'Sovit 1985, is atypisch in dit opzicht ondathet geen 'Sovjetpropagand. is, en ook 'en verheerlijking van De Grote Patriottische oorlog'vernijdt. Het verde belangrijkste slachtoffers in een oorlog

HET EERSTE ZEGEL: ONTSTAANSGESCHIEDENIS Kom en kijk werd uitgebracht naar aanleiding van de veertigste verjaardag van het einde van de Tweede Wereldool g. De rolprent is het resultaat van het professionele en Detionele engagement van zijn makers, regisseur Elem Klimov en scenarist Ales Adamovits. de film wordt getoond. Klimov werd in 1933 gie in de film wordt getoond. Klimov werd in 1933 geboren in Stalingrad en was een bevoonte getuige van de lo zomer van 19.2. In oktober van dat jaar ontvlucht hij stad. Ze steken de Wolga over op een geïmproviseerd vlot om daarna hun heil te zoeken in het Oeralgebergte regiseur vov meente reeft geet ove Coine and See, de beterbekendetitel, wordt snel duidelijk dat de film als catharsis diende om de gruwelijkheden waarvan hij getuige was geweest een plaats te geven.

en de film te maken is de politieke situatie in de Sovjet-Unie eind jaren zeventig. Voor de glasnost zijn intrede doet vanaf midden jaren tachtig, bereikt de Koude Oorlog een absoluut hoogtepunt. Klike oorlog opduiken en redeneert dat als hij nog éen film verschijnt eerst nog zijn bijzonder barolz. In 1975 tueuze tueuze Agony. De film, die een psychologisch portre wordt onmiddellijk in de ban geslagen Noor de Sovwordt oniteiten wegens de te jetautoriteiten wegens de te genuanceerde kijk op Nicolas II en de expliciete orgieën. Klimov zelf is ook

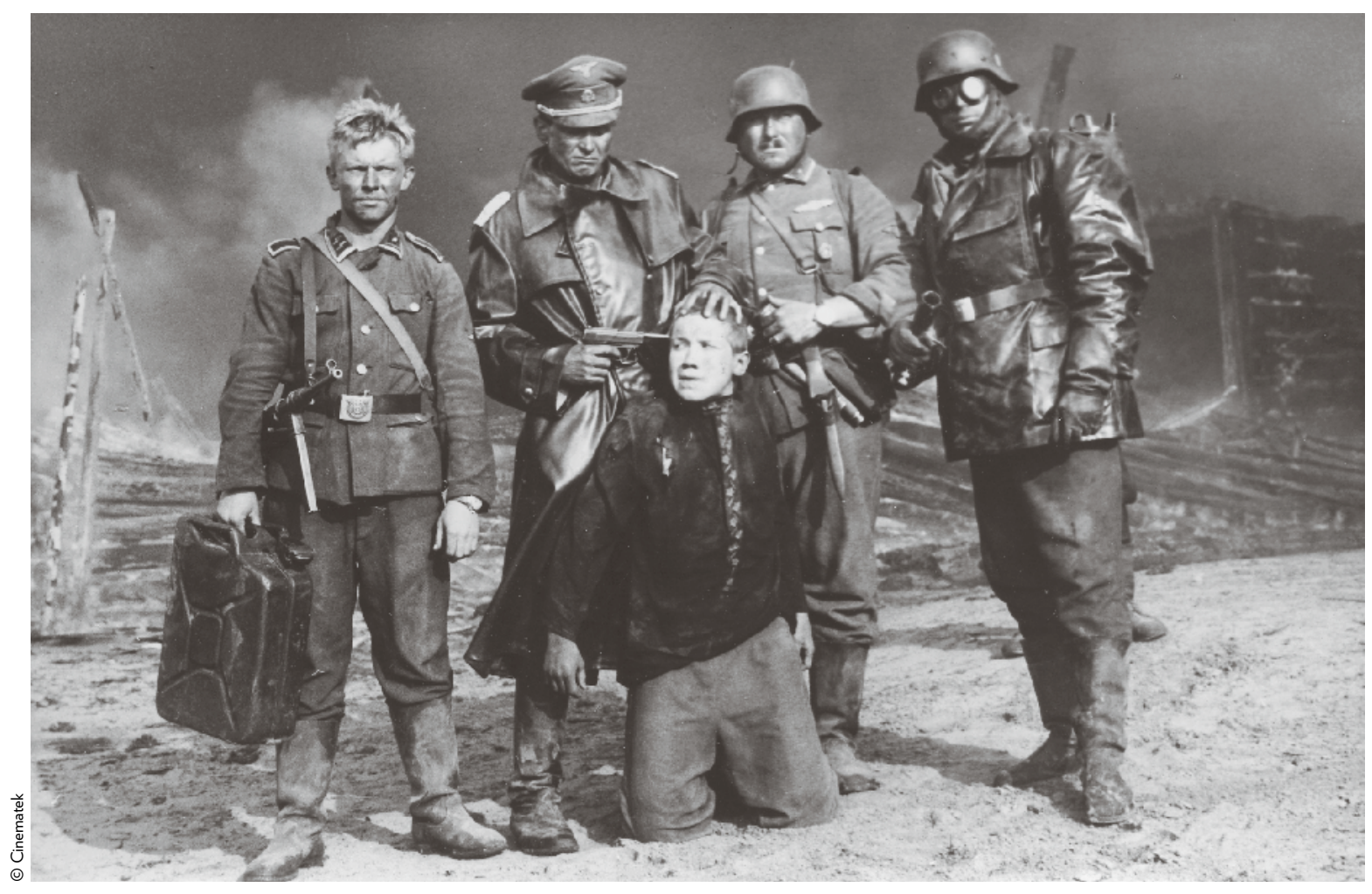

teleurgesteld en verliest de belangstelling in zijn werk Tot overmaat van ramp overlijdt in 1979 zijn vrouw en muze Larisa Sjepitko, de gerenommeerde regisseurvan de film The Ascent, in een auto-ongeluk.

Uiteindelijk slaagt Klimov erin om zich te herpakken. Zijn nieuwe film moet zowel op artistiek als op psychologisch vlak boven Agony uitstijgen en voor ee comeback zorgen. De ontmoeting met schrijver Ale Adamovitsj brengt de zaak in een stroomversnelling De heren vinden elkaar door hun gelijkaardige oorlogservarngen. De ovendt van zijn tijd bij de partizan in wit-Ruslandgeeft een extra dimentillect. Een vroege versievanhetscipt he de titel Kill Hitler, een verwijzing naar het feit dat we nooit mogen toegeven aan rassenté voor de cin voor de and. Goskino, het spreken over de titel en het realise, is idee lijis or tillel en het realisme van de film. Het de broer van Elem Klimov, de titel Comeer German, de broer van Elen Kly A de titel Comeand Seevoorstelt, afgeleid van de Apocalyps van Johannes, krijg tot in 1984 du nouw inpuls. Het zal uiteindelijk tot in 1984 dur voor Klimor Adamovits doen geen toegevingen in Klimov en Adanovitsj doen geen to scenario of de realistische stijl.

HET TWEEDE ZEGEL: KINDERLIJKE ONSCHULD VERSUS YOLWASSEN YERD ORYENHEID

De beleving van de kindertijd tijdens de oorlog op een evenwichtige manier vatten op pellicule is een hekele onderneming. Het was voor Elenn Klinov ook van essentieelbelangdatde dertienjarige hoofdrolspeler AlekseiKravtsjenkogeen trauna'sopliep tijdens contextvanu Rusico vert de rex huscico vertelt de regisseur dat hij onder andere een ver de jeed op hypnologen on het onderbewnstijn te te besch stonden.

De film opent met Flyora en zijn vriendje die spelen op het strand. Het tafereel krijgt snel een sinistere ondertoon wanneer blijkt dat ze geen zandkasteel aa boer uit het dorp warschuwt hen dat ze het ven. Een boer uit het dorp waarschuwt hen dat ze het verlede beter laten rusten. Het is het eerste contrast tusse we aantreffen in de film. De kinderen zijn jong en onbe- zonnen, de boer is oud en heeft geleefd. Met het wapen ls statussymbool wil de jongeling zich aansluiten bij de 'moedige' partizanen. De scène waarin Flyora in zijn zwarte jas inclusief rugzak en geweer voor zij moeder poseert, heeft veel weg van de uitgelatenheid van kinderen op hun eerste schooldag.

te wee inde van de film deen opgezocht. De jongen is op het che viju oneerd en bedrogen door vriend en vijand. Als hij de kns krijgt om op een sych manier Hitler, gijpt hij die kans metbeide hand Hitler, grijpt hij die kans met beide handen. Hij schiet keren Wat volgt is een historisch terugspoeleffect: gan . Wug in de tijd en zien bommen die weer in gaan terug in de tijd en zien bommen die weer in de Duitsland en Hitler die trazsorme tert van man na kind. Het beld van Hitler als baby is wan man naar Flyor oel 'afstraffing' te sto baby is een teken voor best hij det kinderen te stoppen. Op dat moment worden op basis van hun toekomstige ik. Het is de worden op basis van hun toekomstige ik. Het is de film.

\section{HET DERDE ZEGEL: CINEMATOGRAFIE}

VAN DE FILM

Regisseur Klimov gebruikt in 1985 een voor de Sovjetcinema nieuwe cinematografische techniek die haa uitwerking niet mist op het grote scherm. Hij maakt veelvuldig gebruik van de steadicam, een camera die devestigd is aan de cameraman, waardoor het lijkt alsof de camera gilijdt over de velden en zanderige straatjes subjectieve we spat in dat je met co pero, on dat je met de personages meeloopt, ondergaat wat $\mathrm{z}$ tenisen die moeilijk of niet te vatten zijn meteen traCole cameravoering.

Come and See is ook bekend geworden door het intelligente spel met 'binnenbeelden'.Zo is er een shot nn de film dat ons de indruk geeft dat Flyora geëxecuteerd wort. Dit is echter schijn, want wanneer de scène ses ènsceneren voor een fotograaf. Als filmpersonages doorbreken de mannen als het ware het gesloten versum van de film, kijken rent in parallelle uni- 


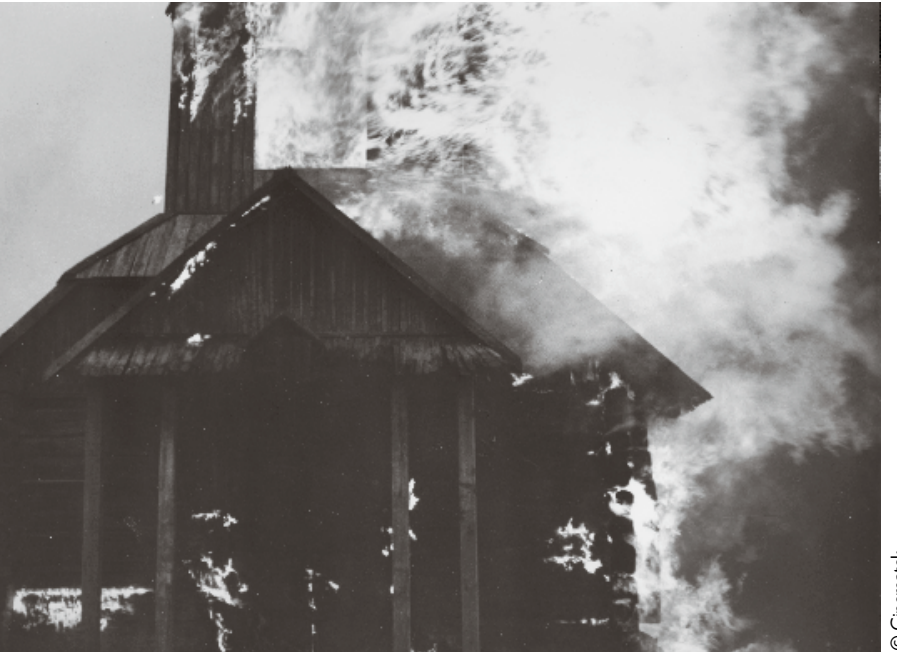

$\bullet$ ook recht in onze ogen (zie Cousins 2005). De cineast geeft met dit beeld kritiek op de wrede, psychologische methodes die de nazi's gebruikten om hun slachtoffers te terroriseren.

\section{HET VIERDE ZEGEL: KRITISCHE ONTVANGST \\ EN PLAATS IN DE SOVJETCINEMA}

Na de release van de film kreeg Come and See van sommige journalisten felle kritiek te slikken omdat ze er een verborgen pro-Russische boodschap in lazen. Ze geloofden dat de film de moordpartij in Katyn door de Russen goedpraatte. In België was filmjournalist Piet Goethals aanhanger van deze these. Hij formuleerde het als volgt:

Katyn vormt een historisch probleem op zich, omdat daar 4500 Poolse officieren door de Stalinisten zouden vermoord zijn. De Russen hebben dit steeds afgezworen en gaven de nazi's de schuld. [...] In feite speelt Klimov in op deze historische ambiguïteit en kiest hij partij voor de Russen onder het mom een antifascistische film gemaakt te hebben. (Goethals 1988, 32-33).

In de bossen van Katyn, nabij de stad Smolensk, schoot de NKVD (de geheime politie van de USSR) in april en mei 1940 inderdaad duizenden leden van de Poolse militaire intelligentsia neer. De nazi's ontdekten de massagraven in 1941 tijdens hun veroveringstocht in de Sovjetunie. Tot 1990 zouden de Sovjetautoriteiten deze misdaad ontkennen. Volgens Goethals schaarde
Klimov zich met zijn film achter het toenmalige discours van Moskou.

Er is hier echter sprake van een misverstand, want Klimov baseerde zijn film op Adamovitsj' boek The Book of Khatyn. Khatyn (mét h) was een dorpje in Wit-Rusland dat in 1943 volledig werd verwoest door het $118^{\mathrm{e}}$ bataljon van de Schutzmannschaft, gevormd door de Oekraïense Hilfspolizei. Met slechts een letter verschil was de fout snel gemaakt, maar het toont aan dat films als Come and See meer en beter bekeken moeten worden om de historische waarde ervan ten volle te kunnen begrijpen.

In de jaren tachtig beantwoordde de Sovjetcinema al lang niet meer aan de sociaal-realistische regels zoals Stalin die voorschreef. Come and See is het eindpunt van een evolutie die al begon kort na Stalins heerschappij. Onderzoekers als Denise Youngblood wijzen erop dat The Cranes are Flying (Kalatozov, 1957), Ivan's Childhood (Tarkovski, 1962), The Ascent (Sjepitko, 1977) en dus ook Come and See (Klimov, 1985) erin geslaagd zijn om een authentieke herinnering te creeren aan het conflict:

By stripping the war of the cant and bombast of official history, by confronting its many paradoxes with unflinching honesty, these moviemakers succeeded where historians had not (and indeed could not, given the strictures of the Soviet historical profession). (Youngblood 2001, 855)

Come and See behoort tot een uiterst beperkte lijst van cinematografische werken die geen politieke agenda dienen en die we zelfs kunnen catalogeren als anti-oorlogsfilm. I

\section{Brecht Capiau}

\section{Come and See van Elem Klimov \\ Dvd Rustico, 2000 - 145 minuten.}

\section{Bibliografie}

Mark Cousins, Close-up: een wereldgeschiedenis van de film, Amsterdam: Van Holkema \& Warendorf, 2005

Piet Goethals, 'Idi i smotri, Die Leiden des jungen Florya', Filmmagie 371, 1988, 32-33.

$\Leftrightarrow$ Denise Youngblood, 'A War Remembered: Soviet Films of the Great Patriotic War', The American Historical Review 106 (3), 2001, 839-856. 